\title{
Elites Intelectuais e a Conformação da Identidade Nacional em Cabo Verde
}

José Carlos Gomes dos Anjos

\section{Resumo}

Este artigo examina dois processos correlacionados à constituição de elites intelectuais em Cabo Verde: a disputa das várias versões sobre a identidade cultural das ilhas e a problemática da mediação política e cultural, isto é, de como diferentes lógicas (política, literárias) se articulam na relação entre a posição de produtor cultural e a condição de mediação cultural e política. Em Cabo Verde essa condição de mediador político-cultural tem sido disputada, ao longo deste século, por grupos que se definem como intelectuais. Além de demonstrar o caráter arbitrário da invenção de "essências" nacionais como a "cabo-verdianidade", pretende-se aqui estabelecer correlações entre as lutas de legitimação das diversas versões de identidade nacional e a constituição de um espaço de mediação entre as multiplicidades culturais locais e as formulações oficiais sobre a identidade nacional e que proporciona importantes lucros materiais e simbólicos àqueles que estão incluídos nessa disputa.

Palavras-chave: identidade, elites intelectuais, mediação política, Cabo Verde, África.

\section{Abstract}

Intellectual elites and the national identity resignation in Cabo Verde

The article studies two processes related to the intellectual elites' constitution in Cabo Verde: the dispute between the several versions about the islands' cultural identity and the questioning concerning political and cultural mediation, this dispute meaning how different kinds of thought (political and literary) are articulated inside the relation between the cultural producer role and the political and cultural 
mediation condition. In Cabo Verde, this political-cultural mediator condition has been disputed, throughout this century, by groups who define themselves as intellectuals. Besides demonstrating the arbitrary characteristic concerning the invention of the national "essence" exemplified by the "cabo-verdianidade", it is intended here to establish a correlation between the attempts of legitimizing different versions of national identity and the constitution of a mediation space between the local cultural multiplicity and the official thought about national identity, which gives material and symbolic profit to those who are included in this dispute.

Keywords: Identity, intellectual elites, political mediation, Cabo Verde, Africa

\section{Résumé}

\section{Les élites intellectuelles et la confirmation de l'identité nationale au Cap Vert}

Cet article s'intéresse à deux processus liés à la constitution d'élites intelectuelles au Cap Vert: la dispute entre les diverses versions relatives à l'identité culturelle des îles et la problématique de la médiation politique et culturelle, c'est-à-dire comment plusieurs logiques (politique, littéraires) s'articulent dans la relation entre la position de producteur culturel et celle de médiation culturelle et politique. Au Cap Vert, cette condition de médiateur politico-culturel a été disputée tout au long de ce siècle par des groupes qui se définissent comme intellectuels. Au-delà de la démonstration du carctère arbitraire de l'invention d'"essences" nationales, comme la "capverdianité", on prétend ici établir des liaisons entre les luttes de légitimation des diverses versions de l'identité nationale et la constitution d'un espace de médiation entre les multiplicités culturelles locales et les formulations officielles sur l'identité nationale; c'est cela qui procure d'importants avantages matériels et symboliques à tous ceux qui prennent part à cette dispute.

Mots-clés: identité, élites intelectuelles, médiation politique, Cap Vert, Afrique. 


\section{Introdução}

objeto deste artigo é analisar a relação entre as elites intelectuais e o nacionalismo em Cabo Verde. Situado a $650 \mathrm{~km} \mathrm{da}$ costa senegalesa, todo o processo de construção da identidade nacional cabo-verdiana tem o Continente africano como referência, seja para uma afirmação de distanciamento, ou para uma afirmação de proximidade ou de pertencimento. Colonizadas por Portugal desde 1460, as ilhas foram povoadas por diversas etnias da parte da costa africana, então conhecida como Guiné. A violência física e simbólica, que destruiu grande parte da memória étnica dos escravizados, tem sido lida pelos intelectuais cabo-verdianos como "fusão cultural de europeus e africanos". Essa "fusão cultural" numa mestiçagem geral é percebida por uma parte da intelectualidade cabo-verdiana como positiva, no sentido de que se teria constituído uma unidade nacional antes da implantação de um Estado nacional. Sob esse prisma, parte da elite cabo-verdiana ostenta com orgulho o seu avanço em direção à modernidade se comparado com as demais naçôes africanas. Sua "fragilidade, em termos de raízes culturais de longa profundidade histórica" (Duarte, 1994:14), é compensada por uma pretensa unidade cultural e racial. Desse modo, estaria esconjurada, definitivamente, a situação de grande parte dos países africanos, constantemente ameaçados de ruptura nacional pelas divisões étnicas mal assimiladas pelo processo de construção de uma unidade nacional sobre um território recortado segundo os interesses exógenos do imperialismo.

Aborda-se, neste artigo, a partir das especificidades cabo-verdianas, em primeiro lugar as discussões sobre identidades racial e nacional; num segundo momento pretende-se uma sociologia da importação e uso emblemático de categorias como instrumentos de lutas sociais. O eixo mais geral de análise é a problemática da mediação política e cultural, mais precisamente, de como diferentes lógicas (políticas, literárias) se articulam na relação en- 
tre posição social, posição de produtor cultural e a condição de mediação cultural e política.

Se a situação empírica em pauta é pertinente para o balizamento das problemáticas conceituais listadas acima, é na medida em que na sociedade cabo-verdiana associam-se demandas por importação de símbolos políticos do Ocidente e a dependência econômica quase total do exterior. Nessa situação, a importação de modelos, instituições, fórmulas e símbolos políticos tende a ser igualmente intensa, o que confere às problemáticas da mediação política e cultural e da importação de modelos uma configuração quase experimental de análise.

A questão do uso social das categorias oriundas das Ciências Sociais ganha uma tonalidade específica e instigante na história do nacionalismo cabo-verdiano. Por um lado as representações intelectuais sobre a gênese da nação cabo-verdiana apresentam Cabo Verde como o caso paradigmático de anulação de diferenças e desigualdades raciais. Por outro lado, constata-se que a trajetória ascendente dos intelectuais, desde fins do século passado, fundamenta-se no acesso limitado às instâncias de importação de modelos e diálogo com a intelectualidade das metrópoles. Resumindo, até fins do século XIX, a sociedade colonizada cabo-verdiana se estruturava sob a dominação racial de uma minoria branca sobre a maioria negra da população; em fins do século XX Cabo Verde é uma sociedade estruturada sob a dominação de elites que, pela manipulação dos códigos político-culturais ocidentais, fazem a mediação entre o sistema internacional e a população local. Desaparecem internamente as contraposições assentadas em critérios raciais e/ou étnicos, ao mesmo tempo em que se reforçam as distâncias culturais, não mais diferenciando grupos étnicos, mas criando elites destacadas pelo desempenho e manipulação dos códigos dominantes ocidentais.

O caso cabo-verdiano pode ser situado no contexto comum das nações africanas, no qual as elites, que questionaram a superioridade racial e cultural européia e que, em alguns casos, empreenderam uma longa luta armada contra o imperialismo europeu e pela libertação nacional, utilizam hoje o domínio dos códigos ocidentais como principal instrumento de dominação interna.

Para os efeitos deste trabalho, não nos interessa tanto a estrutura interna da economia e da sociedade cabo-verdianas nessa passagem da dominação racial, até fins do século passado, para a atual dominação de elites nativas formadas no Ocidente. Buscamos sobretudo o jogo de imposição de novas classificações e princípios de 
identidade que se expressam nos diferentes estados do campo intelectual e político ao longo deste século.

O caráter insólito desse processo cabo-verdiano de dissolução e restauração de modalidades racistas de dominação pode ajudar-nos a revelar princípios de visão de mundo e estruturas mentais, que tendo sobrevivido a mudanças objetivas - como o desaparecimento de um contingente de ascendência exclusivamente européia - estão de tal modo incorporadas e eufemizadas que raramente são contestáveis.

Nas peculiaridades dessa situação empírica, os temas listados (sobre os fundamentos das classificaçôes e tomadas de posições identitárias, a formação de elites, a importação de modelos políticos e sobre as condiçôes de mediação político-cultural entre grupos orientados para a comunidade e aqueles orientados para a nação) adquirem toda uma "atualidade sensível que possibilita pensar não apenas realista e concretamente sobre eles, mas, o que é mais importante, criativa e imaginativamente com eles" (Geertz, 1978:34). Não temos a pretensão de aqui resenhar o conjunto da bibliografia sobre esses assuntos, já que nos cabe apenas situar este trabalho no ponto de extensão e aprofundamento dessas problemáticas com relação à situação empírica em análise. É isso que faremos, em seguida, para cada uma das problemáticas específicas, buscando sempre mantê-las articuladas entre si.

\section{Concepção racial da intelectualidade cabo-verdiana}

Com relação à primeira das problemáticas conceituais listadas acima, aquela do uso social das classificações raciais, o que a situação empírica que tomamos para a análise confere de revelador é a forma como, em diversas conjunturas ao longo de quase um século, a definição da identidade local como mestiça insere-se num conjunto de práticas de mediação entre a população do arquipélago e a metrópole - Portugal.

A afirmação de Sansone, para a situação atual brasileira, de que "a mestiçagem, além de fenômeno biológico, pode também ser considerada um estilo de vida e uma maneira de pensar o mundo, envolvendo cordialidade" (Sansone, 1996:214), adquire, na situação cabo-verdiana, toda uma outra conotação que, em vários aspectos, poderia, inclusive, lançar novas pistas de análise sobre a situação brasileira. Exploraremos, sobretudo na conclusão, as possibilidades de tal estudo comparativo. Por enquanto, sugerimos 
uma outra leitura passível de ser comum à "cordialidade brasileira" e à "morabeza" cabo-verdiana. A categoria cabo-verdiana "morabeza", correspondente à "cordialidade brasileira", pode ser analisada enquanto inserida numa estratégia de dominação, tomando a conotação moral da "abertura em relação ao estrangeiro". Nossa argumentação não vai apenas na direção apontada por Sansone e pelos ideólogos da crioulitude caribenha que diz que as sociedades definidas como mestiças são sociedades particularmente aptas a englobar e transformar símbolos e influências que provêm de outros lugares (ver Mintz \& Price, 1985). Pretendemos, inversamente, verificar em que medida, pelo menos no caso específico da sociedade cabo-verdiana, as elites fundam sua dominação sobre a fratura entre modelos simbólicos importados e a cultura local. Uma sociedade cujas estruturas estatais são exteriores à cultura da maioria da população é uma sociedade fraturada entre a elite, que tem acesso aos códigos ocidentais, e o resto. Nesse sentido, a mestiçagem aparece não apenas como a ideologia que alivia as tensões internas propondo uma imagem de coletividade homogênea, mas é também um modelo de (Geertz, 1978) encompassamento de diferenças, que operacionaliza a forma como modelos simbólicos exteriores podem ser integrados e, por fim, justifica essa importação.

Para se compreender como a categoria mestiço ocupa esse lugar-chave na cultura dominante cabo-verdiana, é indispensável alicerçar a crítica a essa categoria na história social da utilização das classificações raciais em Cabo Verde.

Nas primeiras décadas do século XX, na Europa, América do Norte e América Latina, o discurso do racismo científico começa a sofrer seus primeiros abalos pela dissociação entre os conceitos de raça e cultura. ${ }^{2}$ É o início de um discurso que, cada vez mais, enfatiza a determinação histórica e cultural dos grupos humanos sobre as determinações biológicas. O discurso de contraposição de raças começa a ceder lugar ao pensamento da mescla de culturas.

Alguns estudos têm debatido se a apologia da mestiçagem cultural nas décadas subseqüentes representa apenas um deslocamento retórico em relação ao cientificismo racista dos finais do século XIX, ou se há, de fato, uma mudança conceitual tal, que se possa falar de um novo paradigma. Martínez-Echazábal (1996:121), estudiosa cubana da questão, em uma série de trabalhos tem defendido que, na verdade, o deslocamento no interior desse discurso sobre raças tem sido mais retórico do que conceitual.

A invenção da identidade mestiça, em Cabo Verde, é caudatária desse deslocamento (seja ele retórico ou conceitual ${ }^{3}$ ) do dis- 
curso do racismo científico ocorrido na Europa e América no início deste século e retomado na América Latina no discurso da mestiçagem, tal como reformulado a partir dos anos 20. Em 1936, Freyre definia a mestiçagem do Nordeste brasileiro como "zona de confraternização" de brancos, negros e mestiços num clima de intimidade e cooperação. Não desaparecem os pólos branco e negro, mesmo que possa ser detectada a presença, "a sombra, ou pelo menos a pinta do indígena ou do negro" (Freyre, 1957:279) no corpo e/ou na alma do branco. Se há aqui uma resignificação cultural da cor, ela é parcial, na medida em que não anula "o alvo, de cabelo louro" como traços identitários, portanto, distintivos, sendo a presença negra, neste caso, reservada ao plano espiritual. Separados na superfície, unidos na profundidade espiritual, união essa simbolizada espiritual e fisicamente por essa crescente massa mestiça.

Em Cabo Verde, mais do que como "zona de confraternização", a mestiçagem é percebida como ponto de anulação dos pólos de antagonismo numa síntese completa, na medida em que não há sequer a separação de superfície. É relevante nesse sentido que, na literatura cabo-verdiana, o fenótipo das personagens não apareça enquanto negro ou branco, é como se o desaparecimento da classe dominante de ascendência européia anulasse qualquer percepção de fenótipo. Nos termos do poeta cabo-verdiano Mariano, o principal teórico da mestiçagem em Cabo Verde da década de 60, "o cabo-verdiano não se dá conta nem da sua cor, nem do seu cabelo, nem das suas feições, enquanto está em Cabo Verde" (Laban, 1992:368). Na reciclagem simbólica do discurso latino da mestiçagem, a intelectualidade cabo-verdiana elimina os pólos branco e negro, vislumbrando a realização completa da mestiçagem.

Enquanto na América Latina a postulação da mestiçagem aponta no sentido de uma cultura (racializada) por vir, que eliminaria as contradições ainda presentes, a peculiaridade do caso cabo-verdiano reside, em primeiro lugar, no fato de os ideólogos da mestiçagem partirem do pressuposto de que, nessas ilhas, a mescla racial-cultural anula o conceito de raça. Em segundo lugar, e por conseqüência, essa enunciação é feita a partir de um ponto diferente (Foucault, 1987:141) com relação à identidade que o enunciador se atribui. No caso cabo-verdiano, é o próprio mestiço que fala de sua mestiçagem, diferentemente do lugar do discurso intelectual sobre a mestiçagem na América Latina, que se faz da posição do vir a ser mestiço (de quem ainda não é completamente), a partir de uma ascendência européia, que fala sobre uma maioria 
mestiça. Um terceiro deslocamento, em relação ao discurso latino, é quanto ao principal destinatário do discurso: enquanto o discurso latino sobre raças constitui um espaço interno de debate sobre as identidades nacionais, o discurso cabo-verdiano visa a convencer a metrópole sobre o papel que o cabo-verdiano deve desempenhar no processo colonial.

A anulação dos signos diacríticos, no plano interno, não significa a ausência de uma concepção racial a partir de parâmetros morfológicos. Na abertura da década de 60, Teixeira de Sousa, médico e uma das eminências da literatura cabo-verdiana, definia o cabo-verdiano entre o "branco-europeu" e o "afro-negro" da seguinte forma:

À estruturação somática - cuja formação se realiza num ritmo necessariamente normal, por isso relativamente lento -, respondeu uma aceleração dos processos culturativos que evoluíram no sentido ascensional de aristocratização [...] a aculturação unilateral pela conquista duma parte e renúncia progressiva da outra. $\mathrm{O}$ substrato afro-negro ressalta mais da estrutura racial do tipo crioulo, da sua índole e exteriorização emocionais, do que das suas tendências intelectuais e das atividades ligadas às especulaçôes do espírito. (Sousa, 1958:8)

Tal definiçãao do ser cabo-verdiano carrega as cinco preposições da versão clássica da doutrina racialista, segundo Todorov (1989:114-117). Em primeiro lugar, reafirma-se a existência de raças sob pressupostos biológicos: pressupõe-se que a "estruturação somática” de brancos e negros permite a classificação dos dois grandes grupos humanos, e que a mestiçagem - do ponto de vista biológico - dar-se-ia como um processo de (re) "estruturação somática" "relativamente lento". Isto é, quando a intelectualidade cabo-verdiana na década de 50 - em grande parte, ainda hoje -, refere-se às raças, assenta-se sobre uma idéia biológica de raça nos termos em que se colocava na Europa no fim do século passado, matizada por conceitos culturalistas como "processos culturativos" e "aculturação".

A segunda premissa subjacente é a da correlação entre características físicas das duas raças e características morais, ou seja, a pressuposição de que seres humanos diferem entre si, também, por características mentais inatas. Vinculam-se brancos às tendências intelectuais e "atividades ligadas às especulaçōes do espírito" (associado a "valores aristocráticos") e a afro-negros atribui-se uma certa "índole e exteriorização emocional". No caso específico da mestiçagem cabo-verdiana, as características morais - predominante- 
mente emocionais - afro-negras teriam sido complementadas pelas tendências brancas intelectuais.

As premissas da determinação do indivíduo pelo grupo racial e da hierarquia única de valores que coloca brancos como superiores aos negros ficam subentendidas na colocação de que o processo de aristocratização do cabo-verdiano é, antes de mais nada, o resultado do cruzamento de raças que coloca o mestiço numa trajetória "ascencional" que vai do negro ao branco. Portanto, o darwinismo social, assim como o evolucionismo, dominantes na Europa do século XIX, é ingrediente implícito da formulação da identidade mestiça cabo-verdiana, pelo menos até a primeira metade deste século.

Finalmente, se levarmos em conta que essa definição do tipo cabo-verdiano tinha um endereço político, visava a resgatar um tratamento diferenciado para o cabo-verdiano em relação aos angolanos, moçambicanos e outros nativos da colonização portuguesa, a quinta premissa racialista fica corroborada: por uma política social fundada num saber sobre as raças. ${ }^{4}$

\section{A identidade nacional}

Dois tipos de perspectiva teórica têm enquadrado a questão do nacionalismo: sob um ponto de vista substancialista buscam-se os fundamentos da construção da nação, os critérios por meio dos quais se pode definir o ser da nação e avalia-se a natureza mais ou menos incompleta das realidades nacionais emergentes, as fronteiras que é necessário dar ao próprio objeto para que ele seja algo palpável e bem delimitado. Esse é o tipo de análise que discute a definição da nação e/ou do nacionalismo a partir dos atributos considerados mais essenciais: a língua, a cultura, o território, a religião...

Geralmente esse tipo de perspectiva acaba se apropriando do tempo sob a forma de uma narrativa mítica em que o passado fornece as justificativas essenciais da nação ao mesmo tempo que no presente se formulam as bases para uma projeção da nação no futuro. A esse respeito, Neiburg (1997) aponta o risco que ronda todas as formulações sobre a nação:

O fato de que para ser compreendida e valorada, toda a formulação sobre a nação tenha que aspirar a essa dupla legitimidade impõe uma ameaça aos estudos sobre mitologias nacionais: a de limitar seu resultado à produção de uma nova versão daqueles mesmos mitos que pretendiam analisar. (Neiburg, 1997:86) 
A segunda perspectiva, a que adotamos aqui, toma as diferentes definições de nação em jogo, em cada situação empírica sob análise, como partes do processo de luta em que categorias (inclusive as oriundas das Ciências Sociais) são idéias-força ou instrumentos utilizados pelos agentes na construção da "realidade nacional". Sob essa perspectiva, ficam sob o crivo da análise as próprias relações das Ciências Sociais com as lutas nacionalistas, na medida em que seus princípios, ostentados sob o estandarte das ciências, convertem-se em princípios de identidade e oposição.

Por outro lado, nossa própria perspectiva sujeita-se a várias outras críticas: pode-se objetar que ela tem normalmente uma caráter intelectualista, na medida em que existem outras narrativas provenientes de outros grupos sociais e que, ao privilegiar, no recorte do objeto, a narrativa do grupo mais exposto às influências ocidentais, estaria se submetendo a análise a uma concepção eurocêntrica e estatal de nação.

Quanto a esse ponto, é nevrálgica a observação de Pinto (1986) de que a escolha de interrogar os textos eruditos mais do que as profundezas da "alma" ou da "mentalidade" do "povo" pode parecer ditada por uma tomada de posição intelectualista "[a ideologia da nação precede o sentimento nacional] apenas se nos esquecermos de que as propriedades ligadas ao modo de engendramento dos princípios de classificação constituem o primeiro objeto que uma análise científica deve considerar" (Pinto, 1986:48). Parece-nos ainda que a questão do etnocentrismo fica mal colocada quando definida ao nível do recorte do objeto. Não é pelo fato de se tomar a intelligentsia e/ou o Estado como delimitaçôes empíricas do objeto de estudo que se está universalizando uma história particular.

Sob essa perspectiva relacional, a identidade nacional de um país é analisada enquanto resultado de lutas sociais, não existindo independentemente dos agentes que disputam o lugar de intérprete e definidor de sua essência.

As elites comerciais e intelectuais cabo-verdianas, desde o século XVI se vincularam ao empreendimento imperialista de Portugal na África negra como mediadores do contato entre as sociedades tradicionais e os portugueses, sobretudo na Guiné-Bissau. É a partir dessa condição de mediadores dessas elites que se produz a identidade mestiça enquanto identidade de um grupo. É interessante a perspectiva de Trajano Filho (1993:15) da sociedade crioula como sociedade que se estrutura em círculos concêntricos em que, no centro, está uma elite lusitanizada que mais se articula e se 
aproxima do reduzido número de europeus (comerciantes e oficiais da administração colonial). Nas bordas desse centro crioulo os recém-chegados - no caso cabo-verdiano -, os camponeses que se aproximam da periferia dos centros urbanos. Até início desse século a grande maioria da população camponesa estava inserida em outros círculos socioculturais com relações pouco intensas com os dois principais centros urbanos: Praia e Mindelo.

O recorte dessa análise toma essa identidade crioula em seu momento de emergência - no início do século -, intelectualizada e formulada enquanto identidade mestiça geral para o conjunto da população cabo-verdiana. Poderíamos ver nessa emergência da identidade mestiça o simples efeito da importação de um modelo identitário externo - a ideologia latino-americana da mestiçagem combinada à intensificação de uma situação de liminaridade entre a africanização e a lusitanização da sociedade crioula.

Não por acaso, será na maior cidade portuária do arquipélago, no auge das transações marítimas pelo porto de Mindelo no início desse século, que a identidade mestiça se expressa numa literatura da elite crioula do arquipélago. Como entreposto situado na zona de contato entre as culturas tradicionais africanas e a metrópole, "a sociedade crioula defronta-se como o dilema de ser liminar e intermediária" (Trajano Filho, 1993:15). Deixar a identidade específica dessa sociedade, dada pela condição de intermediação, submergir em uma das duas vertentes mais amplas - a lusitanidade ou a africanidade - é o perigo que, rondando a sociedade crioula, estimularia a obsessão pela questão da identidade - segundo Trajano Filho.

Pretendemos conjugar nesta análise um terceiro componente que se acresce aos dois anteriores, à situação de liminaridade da sociedade crioula entre Portugal e as comunidades tradicionais africanas e à disponibilidade de um modelo externo para pensar a situação de intermediação - o modelo da mestiçagem tal como formulado por intelectuais no Brasil. O terceiro componente a ser analisado quanto às bases sociais da definição cabo-verdiana da mestiçagem é a questão dos múltiplos interesses da elite intelectual das ilhas. Efetivamente, a identidade mestiça só é enunciada como identidade geral para a população das ilhas quando a ampliação do espaço de exercício da administração colonial vocaciona os intelectuais cabo-verdianos para cargos intermediários na administração das demais colônias portuguesas em África. Urgia, então, entre as décadas de 1920 e 1950, desembaraçar a província de origem desses funcionários dos sinais de uma pura africanidade. Mestiço, 
portanto distinto dos demais nativos, o intelectual cabo-verdiano é o mediador por excelência da colonização portuguesa em África. É o conjunto desses componentes que torna a questão da identidade cabo-verdiana tão debatida no seio da elite intelectual de Mindelo na primeira metade deste século. ${ }^{5}$ A obsessão em definir o "povo cabo-verdiano" como não sendo nem português nem africano é a problemática de uma elite familiarizada com os valores básicos da cultura européia, mas colocado como cidadão de segunda classe no império português. $\mathrm{O}$ primeiro par de contraste, Cabo Verde versus África, distingue a elite cabo-verdiana como dotada da capacidade de lidar com os códigos ocidentais. O segundo par de oposição, Cabo Verde versus Portugal, cria as condições para reivindicações regionalistas fundamentadas em projeto de inserção na administração colonial.

A ruptura com o Estado colonial e a reivindicação nacionalista só se dá na década de 60 , quando o crescimento do número de intelectuais ao nível de Cabo-Verde esbarra na ausência de espaços de inserção e ascensão nos quadros da administração colonial.

Cabo Verde - imaginado como a nação mestiça por excelência - a é a ficção da possibilidade de se engendrar um grupo corporado a partir das relações de dependência em relação ao Ocidente. A possibilidade de se engendrar grupos corporados a partir de relações diádicas passa pela transcendentalização do grupo, por esse ato de sacralização que torna imortal o corpo social. Daí os atos de "naturalização" da identidade de grupo: fundada na natureza, por isso eterna.

A descolonização, a seu modo, reconstrói a epopéia da gênese Européia do Estado moderno esmerando-se em garantir a "unificação do território ou, mais exatamente, a construção, na realidade e nas representações, do Estado como território unitário, como realidade unificada para a submissão às mesmas obrigações" (Bourdieu, 1993:54).

É importante concentrarmo-nos na seguinte nota de Pinto (1986) de que a nação não se edifica sob a ruptura completa com a fidelidade pessoal, ela reformula-a. Na idade média européia, mais precisamente no século XIII, a sociedade política, escapando simultaneamente aos particularismos locais da fidelidade, ao universalismo cristão e à fidelidade pessoal, produziu a representação de societas civilis, com suas ordens em vias de formação e sua consciência de comunidade. 
Simplificando e esquematizando muito (passando aqui para o nível da teoria política) diria que o nacionalismo moderno nada mais é do que a associação de elementos teóricos que não se juntaram ao de "comunidade política" senão após a Antiguidade: do conceito de "comunidade política" (autoridade, origem e exercício do poder e do direito à soberania, pessoa jurídica, contrato social etc.) e do conceito original de lealdade política, isto é, de "fidelidade", no quadro muito antigo da "nacionalidade” que por esse fato torna-se a nação moderna. (Pinto, 1986:46)

No caso cabo-verdiano é como se a fidelidade ao patrão ganhasse um conteúdo transcendente: fidelidade à nação. Essa redefinição não rompe como o princípio da fidelidade que sustenta o clientelismo. Essa problemática da construção da identidade nacional se liga assim ao tema do clientelismo, que por sua vez remete à reciprocidade e à temática da dádiva, tratados primeiramente por Malinowski (1976) e por Mauss (1974).

Vários autores, nomeadamente Legendre (1976), Lagroye (1985), têm explorado o tema do dom no exercício legítimo do poder nas sociedades modernas. Se é difícil seguir Legendre quando este vincula às manifestações simbólicas Estados burocráticos contemporâneos ao direito, dividindo-o entre o direito público situado do lado do puro, do nobre, da dádiva sem contrapartida, enquanto o direito privado estaria do lado do impuro, certamente é pertinente analisar as manifestações da "velha" concepção do poder doador em outros fenômenos como as redes de clientela "intersticiais, suplementárias ou paralelas" ao sistema institucional de poderes (Wolf, 1980).

No caso cabo-verdiano, mais do que isso, a nação e seus governantes se constituem como o núcleo de um imaginário do poder como doador e como mediador de doações. É na imagem de um país sem recursos, que recebe ajuda das potências estrangeiras e as redistribui para a população garantindo a sobrevivência desta, que se edifica uma concepção global e personalizada do poder.

O que exploramos neste trabalho é a hipótese de que - no caso cabo-verdiano - uma identidade assentada sobre uma certa noção de fidelidade (o crioulo como o dependente do senhor branco), ao elevar-se a identidade nacional manter os esquemas de pensamento e as relaçóes sociais da qual se originou. Pretendo que na concepção de mestiçagem está inserido um modelo de relação de reciprocidade branco-nativo, com o qual a concepção de nação não rompe, mas sim reformula. Isso tanto para o nacionalismo enquanto doutrina e como sentimento nacional (Smith, 1979:168). 
O deslocamento da soberania que antes residia nos símbolos portugueses, para os novos símbolos de uma nova identidade emergente - a identidade nacional cabo-verdiana - certamente exigirá uma reinterpretação das categorias éticas ligadas à sujeição pessoal. Assim se produz um deslocamento da própria criolitude que de símbolo de fidelidade pessoal ascende a símbolo de identidade nacional.

A nação - como comunidade imaginária - constitui-se nesse deslocamento da sujeição pessoal à dependência internacional com relação às potências ocidentais "doadoras", "financiadoras" e "investidoras". Em outro trabalho (Anjos, 2002) utilizamos o conceito de patronagem internacional, nos termos de Dezalay, como relação "tanto mais difusa quanto repousa sobre linhas de relações pessoais e que ela se inscreve nos saberes". Com efeito, ela cria nos "Estados-clientes" toda uma categoria de clero que deve o essencial de sua legitimidade e, portanto, muitas vezes também as posições privilegiadas que detêm no aparelho de Estado - a um saber ocidental de que são os depositários e os importadores (Dezalay, 1995:29). Se o dois termos - Cabo Verde como nação (cliente) e o Ocidente como potência (patrão) são construtos em grande parte imaginários, a atualização concreta dessas construções permite à elite político-intelectual cabo-verdiana se sustentar politicamente como intermediária privilegiada dessas doações, financiamentos e investimentos. É através das estratégias de importação de modelos simbólicos do Ocidente para a configuração da nação que essa elite se constitui como cliente numa relação de patronagem internacional.

Não desprezamos aqui a possibilidade de haver outras narrativas nacionalistas que não as da elite intelectual vinculada ao Estado, mas, para os objetivos deste trabalho, trata-se, basicamente, de expor as propriedades ligadas ao modo de produção dos princípios de classificação, que, estando na base da definição da identidade nacional, foram institucionalizados e consagrados pelo Estado. As identidades sociais legitimadas enquanto identidades nacionais pela sanção de uma autoridade Estatal competem de forma desigual com outras narrativas de identidade na medida em que "o Estado, que dispóe de meios de impor e de inculcar princípios duráveis de visão e de divisão conforme a suas próprias estruturas, é o lugar por excelência de concentração e exercício de poder simbólico" (Bourdieu, 1993:55).

Através do sistema de ensino, o Estado consagra e repassa as narrativas (sobretudo literárias e históricas) que constituem a na- 
ção enquanto conjunto definido de representações com as quais os indivíduos de um determinado espaço social e geográfico devem se identificar.

Isso não significa que esses princípios dominantes de identidade - impostos principalmente pelo sistema de ensino - não possam ser reavaliados pelos grupos e classes dominados de acordo com os respectivos ethos. Porém, mais do que as reelaborações práticas, interessam-nos as propriedades ligadas ao modo de engendramento dos princípios de classificação fundamentais na definição da identidade nacional.

É certo também que as próprias narrativas populares tendem a ser reatualizadas ou reinventadas pelo Estado sob a forma de coleta de tradições (orais) consagradas e repassadas para o sistema de ensino. Assim, as contradiçôes inerentes à importação de modelos exteriores de autoridade sobre a necessidade de ostentar valores próprios é um dos campos fecundos para a análise.

Pretendemos tomar a mestiçagem como ícone de uma narrativa elaborada pelas elites cabo-verdianas que atua junto às populações que têm acesso à escolarização e aos meios de comunicação de massa, no sentido da construção da identidade nacional. A narrativa do processo da mestiçagem tem um grande poder retórico no sentido de demarcar e manter fronteiras entre a comunidade imaginada - Cabo Verde - e as referências de contraposição: a África e Portugal. Essa narrativa emerge de forma típica na fala do escritor já citado, Teixeira de Sousa, uma dos mais acérrimos defensores da mestiçagem:

O povoamento das ilhas foi iniciado, pouco depois do seu achamento (1460), com africanos e portugueses. Ao longo de séculos, foram trazidos para o arquipélago contingentes africanos de diversas etnias. Desenraizados das culturas de origem, esses grupos étnicos haviam forçosamente de olvidar os valores próprios para se integrarem noutros padrões, embora num processo de transculturação entre colono e colonizado que viria mais tarde a definir a identidade cultural cabo-verdiana. Identidade cultural que hoje se confunde com a identidade nacional. Ao fim e ao cabo, o meu país deixou de ser África e deixou também de ser Europa para apenas ser Cabo Verde. (Laban, 1992:205)

A narrativa do processo de mestiçagem define a cabo-verdianidade no espaço, no tempo e na concepção de pessoa. $\mathrm{O}$ espaço das ilhas, enquanto deslocado do Continente, estabelece-se na narrativa como fronteira "natural". No tempo, cinco séculos de encontro entre portugueses e africanos teriam definido essa unidade fundamental da nação que é a pessoa cabo-verdiana. Nesse sen- 
tido, analisamos a mestiçagem como termo-síntese de um mito de fundação da nacionalidade.

Ao apresentarem-se as evidências de uma mestiçagem geral, que teria atingido a todos os cabo-verdianos, a operação essencialmente política de montagem de uma unidade nacional nos é apresentada como processo "natural" - o fenótipo é naturalmente mestiço; logo, a unidade nacional está naturalmente alicerçada por essa evidência biológica que a todos atinge. A naturalização da mestiçagem, cujo modelo é dado pelo fenótipo, reaparece na língua, na culinária e na música. Toda uma série de signos são exibidos como distintivos de uma essência mestiça.

Entre os obstáculos que o estudo científico da constituição da identidade deverá transpor, o mais importante é certamente constituído pelo obstáculo essencialista: ele resulta, com certeza, da tendência de apreender os grupos de forma ingenuamente realista encontrando neles mesmos seu princípio explicativo; mais resulta também da lógica de sacralização ideológica que implica em celebrar a identidade do grupo pela negação das contingências históricas. Pode se ver em qualquer populismo [...] a forma acabada de um discurso de legitimação visando fundar a nação na natureza. (Pinto,1986:46)

Todos os grandes empreendimentos políticos em Cabo Verde, desde o fim do século passado, precisaram se fundamentar num discurso racialista-culturalista que constitui e unifica o povo cabo-verdiano, seja na mestiçagem ou na africanidade. A naturalização do grupo sobre uma territorialidade, como a que confere autoridade e justificativa ao empreendimento nacionalista, já foi ressaltada por vários autores, nomeadamente Smith (1979) e Shafer (1955). No caso cabo-verdiano, é sobre uma definição racial homogênea que se disputa a "natureza" da nação."

É a partir de uma identidade de grupo, fundada em relações de reciprocidade, que emergiu a identidade mestiça. Pretendo mostrar que essa identidade mestiça só muito recentemente se apresentou como identidade geral de todos os cabo-verdianos e, mais recentemente ainda, ela busca apresentar-se como a identidade nacional. Essa identidade, elaborada nos círculos intelectuais, sobrepõe-se às identidades locais dos bairros, das vilas, das ilhas e das formas de religiosidade, com a pretensão de unificá-las numa essência comum e natural: a mestiçagem cultural e biológica.

A naturalização da identidade cabo-verdiana na mestiçagem, até a primeira metade deste século, não implicou numa postura nacionalista. Quando, na década de 60, emerge um movimento de reivindicação nacionalista - conformando o Partido 
Africano para a Independência da Guiné e Cabo Verde (PAIGC) é numa concepção contrária à ideologia da mestiçagem, isto é, no resgate da africanidade do arquipélago.

Tanto a reivindicação regionalista da primeira metade do século, que institui uma elite literária cabo-verdiana, quanto o movimento de libertação nacional, fundamentam na natureza racial da população uma identidade que territorializa o arquipélago. Se, na década de 90, o processo de abertura democrática institucionaliza de novo a identidade mestiça como a essência da nação cabo-verdiana, o trabalho do antropólogo, menos do que o de definir qual dessas identidades corresponde de fato à essência nacional, é o de "desconstruir o trabalho de universalização imposto a todos os grupos sociais de se reconhecer numa categoria política, cuja aparição está ligada a interesses sociais historicamente condicionados" (Pinto, 1986:46).

\section{O intelectual como produtor cultural e como mediador}

O caso cabo-verdiano é mais uma demonstração do quanto as identidades (sobretudo as nacionais) são fluidas, de como se desmancham e se recompõem no tempo, do quanto mudam, retornam e desaparecem. O que se pretende evidenciar aqui é o caráter ideológico da identidade nacional, no sentido de construto mental que visa legitimar construções e relações políticas. Sob esse aspecto, as diferentes versões da identidade nacional adotadas pelas elites politicamente dominantes buscam construir a "evidência" de que as principais opções da governação estão fundadas nos "traços" mais sólidos da identidade do "povo".

Se o estudo da identidade nacional não pode ser reduzido ao seu aspecto ideológico, certamente sua proclamação pelos "mediadores", numa situação marcada por certas relações de poder, exige da análise um enfoque privilegiado sob o quanto essas identidades mascaram, legitimam, justificam, servem de modelo para ou de ações de poder.

No caso da identidade cultural forjada pelos intelectuais cabo-verdianos, se tem enfatizado, além da mestiçagem, os temas também míticos das grandes secas e mortandades que teriam homogenizado cultural e socialmente os diversos estratos da população cabo-verdiana. Certamente, a imagem recriada e repetida na literatura (ensinada ao longo de toda a adolescência) dos cenários de fome funciona como uma memória extremamente violenta que 
imprime nos espíritos a imagem da morte física dos indivíduos que compõem o grupo e, portanto, da ameaça latente de desaparecimento do grupo. Seu poderoso narcótico reside no fato de se associar a ameaça da morte abstrata do grupo à necessidade individual de se continuar subsistindo.

Não sendo mero derivado das heterogêneas culturas dos múltiplos grupos, ilhados não apenas geograficamente, a proclamação da identidade nacional muda as culturas, pela mobilização emblemática de alguns traços que, sendo superestimados, levam a desequilíbrios nas anteriores correlações de valores. A construção da identidade nacional supõe, portanto, um trabalho sobre as culturas particulares. Mais precisamente,

o acesso de uma língua ou de uma cultura particular ao universalismo tem como efeito reenviar os outros à particularidade; em outros termos, pelo fato de que a universalização das exigências assim instituídas não se faça acompanhar da universalização do acesso aos meios de satisfazê-lo, ela favorece simultaneamente a monopolização do universal por alguns e a não-posse de todos os outros, assim mutilados, de alguma forma, em sua humanidade (Bourdieu, 1993:55)

Esse trabalho sobre as culturas se dá por uma reapropriação do espaço e do tempo pela linguagem mítica do poder, sendo o espaço percebido como o lugar que fornece (e retira) as condições de vida material para a reprodução do grupo e, que, portanto recria formas específicas de sociabilidade. Nos termos de determinados arautos da mestiçagem, é a peculiaridade do espaço cabo-verdiano que fez com que negros e brancos colocados numa situação de insularidade e de carência material de espaço quase inóspito se fundissem numa cultura original.

A apropriação do tempo nessa linguagem mítica se dá, por um lado, por uma espécie de "amnésia" que visa eliminar das consciências formas de expressão de experiências que possam colocar em risco a unidade do grupo. Por outro lado, o passado se torna particularmente propício à "invenção de tradições", atividade essa hoje em grande parte estatizada num setor do Ministério da Cultura - o Instituto Cabo-verdiano de Investigação Cultural (INIC) que tem como projeto coletar traços tradicionais antes que desapareçam sob o efeito da modernização. Martin (1992:586) conceitua como "intemediários" a esse tipo de atores sociais especializados na harmonização da identidade política:

O processo de construção identitário vai consistir em harmonizar, de um lado, as estratégias em vistas do poder por um grupo de "intermediários" 
políticos e, de outro, sentimentos difusos compartilhados por uma parte tão vasta quanto possível da população [...]. A identidade supõe a eliminação, o recalque, mesmo que temporário, de tudo o que pode dividir; ela impõe um núcleo ou mais, de aglutinação, ao lado dos quais outros elementos do vivido devem ser considerados secundários. (Martin, 1992:587)

A comunidade nacional recriada por essa apropriação mítica do espaço e do tempo é, em todo o caso, uma "comunidade imaginária", na expressão que Anderson (1993) cunhou para o senso comum antropológico.

É comum também à abordagem clássica da antropologia da identidade (Barth, 1976), tomar a construção e a qualificação da identidade como o resultado de um mecanismo dialógico: a construção de Si com relação aos Outros é indissociável da definição de si pelos Outros, sendo que tanto as endodefinições como as exodefinições são móveis, podendo existir várias exodefinições de um mesmo grupo. O que se destaca no caso das identidades mestiças é a forma como a exodefinição é incorporada pelo grupo estigmatizado (na categoria mestiço) como estratégia de reforço da estigmatização de um outro grupo que não aquele que o definiu como tal. $\mathrm{O}$ mestiço se assume como tal ao se vislumbrar como sendo superior ao negro. Tal como a tendência geral o indica, no processo de construção dessa identidade dominada, o arauto da mestiçagem lança mão da linguagem do dominador a fim de proclamar a positividade de seu "ser" coletivo. Assim o fazendo, ele reforça os princípios hierárquicos estabelecidos pelo dominador.

É claro que esse processo de identificação e estigmatização, aderência ao estigma e reforço do estigma sobre um terceiro não pode ser analisado apenas sob o ângulo da manipulação. Para a maioria dos que encarnam uma determinada identidade, estão em jogo sentimentos difusos, freqüentemente elaborados sob os registros do medo, angústia, revolta diante da dominação e da exploração. Porém, os mediadores (literatos, ideólogos, políticos) poucas vezes escondem os objetivos mobilizadores que os levam a defender determinadas identidades em detrimento de outras, a dizer que o grupo existe sob determinadas insígnias, a produzir narrações míticas para se apropriarem do passado e conformá-lo aos seus projetos atuais.

Resumindo, algumas das conjunturas de transformaçôes sociais em Cabo Verde, à luz dessa perspectiva de análise exposta acima: a primeira dessas conjunturas é a da virada do século em que os morgadios começam a entrar numa decadência, cujo golpe final se- 
ria dado pelo Banco Nacional Ultramarino na década de 20. As mudanças na estrutura social que levam a um processo crescente de diferenciação social contudo não atenuam o grau de estruturação social sobre a base da dependência pessoal, mesmo que provocando alterações na estrutura de distribuição e concentração da dependência. A agricultura reduzida à subsistência e ameaçada pelos freqüentes anos de seca diminuem a importância do controle da terra como recurso que pode assegurar a proteção das clientelas. Ao longo do século, a esperança de proteção passa cada vez mais a ser depositada na possibilidade de intervenção de forças externas ao universo local. O controle das relações com a administração colonial $^{8}$ se transforma em recurso-chave de mediação. Funcionários de nível intermediário, os primeiros intelectuais cabo-verdianos, disputavam os cargos da administração ao mesmo tempo em que intercediam a favor do "povo cabo-verdiano". Faziam da publicação de poesias o veículo de auto-apresentaçáo e reconhecimento junto à administração colonialista e vinculavam a resolução dos "problemas" do arquipélago a sua intervenção e solicitações junto à administração colonial.

Uma segunda conjuntura de forte reestruturação das relações sociais no arquipélago se dá na década de 30 e tem como marco simbólico o aparecimento da revista Claridade. O contexto é o da ditadura salazarista, instalada em 1926, que limita violentamente as aspirações nativas e, portanto, atenua a tensão na disputa nativos-metropolitanos pelos cargos administrativos na província. Daí a necessidade de reforço dos canais de mediação "cultural" (entre as quais se destaca a revista Claridade) para a formulação das "demandas populares". Processa-se a mediação das necessidades locais por meio de cartas de intercessão dirigidas à administração e, sobretudo, por meio da criação de um poderoso imaginário da seca e da fome por vias literárias. Não apenas cartas dirigidas à administração - o que já era um canal para a geração do seminário-, mas também romances e poesias falando da "seca" e do "sofrimento" do "povo cabo-verdiano" constituíram a geração Claridade como um importante mediador cultural entre as demandas locais e o sistema colonial. É nessa conjuntura de intensa produção em nome da "cultura" e quase sem atividades exibidas como "políticas" que emerge o imaginário de Cabo Verde como comunidade.

As duas últimas conjunturas de intensa mobilização de símbolos nacionalistas foram a segunda metade da década de 1970, a era dos combatentes, e o fim da década de 1990, com a abertura política, a era dos quadros. Com a independência nacional, é o con- 
trole dos cargos do Estado o que assegura a mediação local e com as instâncias internacionais. Durante a Primeira República se estabelece uma rede de mediações com base em princípios de reciprocidade que assegura a ascensão social privilegiada aos mais afetos aos combatentes.

Após a década de 90 é o período da mediação exercido privilegiadamente pelos quadros. O que se mantém constante é que os novos e antigos literatos, os experts da importação dos mais variados modelos simbólicos do Ocidente, e os ocupantes dos principais cargos políticos estão ligados aos círculos do poder e saber ocidentais por linhas de patronagem e clientelismo.

Um traço que essas quatro conjunturas de transformações nas relações de mediação carregam em comum é a crença de todos esses grupos poderosos de sucessivos de empreendedores da identidade cabo-verdiana, que se definem como intelectuais, de que Cabo Verde só subsiste por uma intervenção "auxiliadora" de instâncias externas. E o controle dessa relação com o "exterior" passa pelo domínio dos códigos ocidentais.

E isso certamente tem a ver com o princípio de extroversão com que essa intelectualidade pensa a identidade cabo-verdiana. O estudo de Niane (1995) sobre Senegal mostra como "as exigências da planetarização da economia" levam a um cosmopolitismo "que impede, recusa ou pelo menos freia toda a postura identitária nacional”. E se isso não é um fenômeno que possa ser lido apenas segundo o prisma atualmente em voga da "globalização", ou seja, da imposição de um modelo de pensamento e de comportamento pelos meta-estados que são as organizaçóes multinacionais ou transnacionais. A sugestão de Niane (ibidem:193) para o caso senegalês e que pode ser estendido para os demais países africanos, guardadas as especificidades, é que as elites nativas desde a colonização sempre se colocam sob uma estratégia de recuperação de desvantagens em relação ao colonizador, primeiramente, e aos agentes e instituições internacionais, após a independência, e depende do domínio dos códigos metropolitanos. Sob uma lógica de que não detêm as regras, investem numa estratégia que os confina à posição dominada de exercer o poder sem deter o poder.

No caso cabo-verdiano, os princípios da própria identidade nacional, sobretudo na sua versão da mestiçagem, já privilegia a exogenidade. A idéia de que Cabo Verde só "sobrevive" à custa disso que o escritor Teixeira de Sousa chama de "sagesse" de sua elite política, que nas relações internacionais significaria habilidade na busca da "ajuda para o desenvolvimento" tanto do bloco socialista 
quanto do Ocidente, não deixa de estar relacionada aos princípios dessa estratégia de exogenidade. Com outros termos, o escritor Germano Almeida repete o mesmo discurso estratégico, sob o mesmo princípio exógeno: "efetivamente Cabo Verde não pode sobreviver sozinho, tem que estar ligado a alguém" (Laban, 1992:675). Sob esse ponto de vista, como constata o artista e depois Ministro da Cultura, Leão Lopes, a "preocupação" com a África, desde o golpe de Estado na Guiné, é mais "político" do que "cultural". Assim, podemos chegar às mesmas conclusões a que chega Niane para o caso do Senegal:

Por seu atraso ou por erro de apreciação, as elites senegalesas [assim como as cabo-verdianas] têm contribuído fortemente, não apenas para a efetivação, mas também para a perpetuação de um poder hipertrofiado, não autônomo com relação aos centros de imposição exteriores. (Niane, 1995:193)

Desde o início do século, quando os intelectuais falam da identidade cabo-verdiana, pensam na cultura como algo associado à raça (no sentido importado das reconstruções conceituais de Gilberto Freyre), para correlacioná-la à Europa e à África (e ainda ao Brasil). Nesse sentido, diferentemente do caso senegalês, desde pelo menos a década de 30 as elites cabo-verdianas não deixaram de elaborar discursos identitários próprios para Cabo Verde, mas paradoxalmente esses discursos e essas posturas nunca foram contrárias ao cosmopolitismo. Criado sob o modelo do exocruzamento, o discurso da mestiçagem é uma importação que modela e justifica o regime de importaçôes subsequente e legitima as estratégias de exogenidade.

O que a análise do caso específico cabo-verdiano tem a contribuir numa discussão mais geral é a pertinência da relação entre importação de bens simbólicos estrangeiros, o clientelismo dominante nas relaçóes internas e com os agentes estrangeiros e os próprios símbolos e conceitualização da identidade nacional. Tentamos analisar como o mito da mestiçagem serve de modelo para ambas as estratégias: da importação e das relações clientelísticas.

Mas as outras versôes da identidade nacional (a lusitanidade e a africanidade) também privilegiam a exogenidade ao recortarem o minúsculo Estado cabo-verdiano como um espaço interno fundamentalmente dependente das forças que lhe são externas. ' As diferentes versões da identidade nacional são aqui princípios de legitimação de vínculos com instâncias externas e que justificam a dominação interna. 
Em todas as suas versões (luso-crioula das primeiras décadas do século, mestiça da Claridade, africana do PAIGC, mestiça e lusófona com o $\mathrm{MpD}$ ), o discurso de reivindicações "nacionalistas" e "culturais" da elite indígena cabo-verdiana imbrica uma estratégia de dominação interna com a submissão a forças externas.

Mesmo na versão mais africana da identidade cabo-verdiana, a lógica da exogenidade acabou modelando de forma paradoxal as práticas políticas implementadas: Cabo Verde não se incorporou à Guiné-Bissau, mantendo esse símbolo da africanidade (de fato a unidade não foi proposta com relação a um país real mas sim com a africanidade que esse país simbolizava), como uma "alteridade" irredutível ao mesmo tempo em que próxima, numa série de laços institucionais e clientelísticos entre as elites dos dois países (ambas se definindo como mestiças e mantendo internamente e externamente símbolos de africanidade próximos, mas nos quais não se deixam dissolver).

Com o golpe de Estado de 14 de novembro de 1985 na Guiné Bissau, e a conseqüente ruptura do binacionalismo, o governo do PAICV pôde enfim, numa série de atos de reconciliação, oficializar sua aproximação dos ideólogos da mestiçagem - nomeadamente a geração Claridade. A posição do governo da primeira república quanto à definição da identidade nacional passa a ser cada vez menos clara. Por um lado, o PAICV, enquanto herdeiro do PAIGC, não podia romper completamente com uma epopéia de libertação nacional que lhe conferia legitimidade política para continuar monopolizando toda a expressão política. Por outro lado, suas vinculações diplomáticas cada vez mais privilegiadas com os Estados Ocidentais, particularmente com Portugal, mais a dependência econômica, faziam com que sua versão africanista parecesse uma retórica ultrapassada que destoava das alianças efetivamente implementadas no campo internacional. Os ideólogos da mestiçagem reconhecem que o governo do PAICV se aproxima satisfatoriamente da Europa, mas mal suportam que os signos da africanidade continuassem "destoando" da "verdadeira" identidade "cultural" cabo-verdiana. Logo após a "abertura política", em 1991, a bandeira nacional (que era semelhante a da Guiné Bissau), foi mudada e um dos deputados justificava o ato alegando em assembléia a diferença cultural e racial do cabo-verdianos em relação aos guineenses.

Em qualquer uma das suas versões, o processo de elaboração e legitimação da identidade cabo-verdiana é o resultado da aplicação de um conjunto de classificações derivadas das ideologias ra- 
cistas européias do século XIX. O princípio de oposição subjacente a essas versões se dá entre África e Europa, que funcionam como pólos que podem ser valorados positiva ou negativamente. Associada a estereótipos raciais, raramente explicitados enquanto tal, a afirmação da identidade cabo-verdiana como mestiça é tão racialista quanto a afirmação da europeidade ou da africanidade.

Da estrutura social de divisões étnicas da escravatura foi herdado todo um mundo de representações raciais, reformuladas na década de 1930 pela incorporação das concepções racistas de Freyre. Apesar do desaparecimento da oposição racial entre brancos e negros em Cabo Verde, as representações raciais persistem como um sistema de crenças e de categorias depositadas na linguagem e perpetuadas pelo uso, como totalizações irredutivelmente práticas e simbólicas, disponíveis e prontas para serem empregadas, sendo simultaneamente significações culturais, crenças e categorias.

Em Cabo Verde, como de resto no Brasil, o discurso mestiço é uma reelaboração do discurso racialista do século XIX. Ele se estabelece a partir de um pequeno número de oposições que geram um termo mediano que anula as negatividades associadas ao pólo africano (negro). Nesse sentido, esse discurso é apenas mais uma variante daquela "revolta contra o estigma, que começa pela reivindicação pública do estigma, constituído assim em emblema" que Bourdieu (1989:125) aponta no paradigma do "black is beautiful". O mestiço valorado negativamente no discurso racialista do século XIX foi tomado como emblema das identidades nacionais de alguns países latino-americanos, reelaborados positivamente e exportados, pelo menos por Freyre, com relação a Cabo Verde.

O discurso da Claridade, nas décadas de 30 e 40, sobre a identidade cabo-verdiana, cada vez mais retomado e prestigiado, abrigado e reproduzido por meio do ensino a título de literatura, pretende que os valores africanos se diluíram "na circunstância da terra, da pobreza, da seca”. Entrevistado por Laban (1992:676), nesses mesmos termos, Germano Almeida, que representa a mais nova geração de intelectuais cabo-verdianos já consagrados, reproduz o mesmo discurso citando a fonte: "Culturalmente, de fato, nós não somos africanos. O Baltasar uma vez respondeu a uma pergunta desse tipo dizendo: 'Isto aqui não é África, é Cabo Verde!' E é verdade".

O patrimônio literário cabo-verdiano, que muda muito lentamente de geração em geração, funciona como uma espécie de forma a priori de sensibilidade incorporada que contém os princípios geradores das atuais formulaçôes da identidade nacional, mas 
que remonta às revelaçóes raciais da década de 1930, elas mesmas elaboraçóes da Claridade a partir do cientificismo racista europeu do século XIX, apropriado de segunda mão e após reelaborações por Gilberto Freyre.

É sob os princípios dessa noção de raça que os intelectuais cabo-verdianos continuam pensando a identidade nacional, sendo cultura um eufemismo que subentende a idéia de raça e permite classificar povos não mais biológica, mas culturalmente. O termo intermediário entre as duas matrizes culturais (européia e africana) situaria Cabo Verde junto ao Brasil, Cuba e talvez toda a América do Sul, segundo formulações recentes do escritor cabo-verdiano mais prestigiado na atualidade, Germano de Almeida.

Mas se a mestiçagem é o melhor modelo de e para (expressão cunhada por Geertz, 1978) a importação de bens simbólicos, é certamente porque seu princípio de universalidade (em contraposição ao particularismo africanista, por exemplo) se realiza na imitação do universalismo imperialista que lhe antecede e ao qual se subordina: a europeidade.

\section{Notas}

1. O interessante trabalho de Kwame Appiah sugere entre outras razões para a persistência das línguas européias como línguas oficiais nas nações independentes da África "a possibilidade menos nobre de que essas línguas estrangeiras, cujo domínio havia marcado a elite colonial, tenham-se transformado em marcas de status preciosas demais para serem abandonadas pela classe que herdou o Estado colonial" (Appiah, 1997:21). Trabalho esse aspecto quanto ao caso específico de Cabo Verde em Anjos (2002).

2. Martínez-Echazábal (1996:109) atribui a Boas (1940) o deslocamento do conceito de raça para o de cultura, posteriormente retomado pelos intelectuais latinos.

3. Em outro trabalho (Anjos, 2002), discuto mais detalhadamente a forma como em Cabo Verde se importa e se transforma o imaginário da mestiçagem nacional.

4. Tratando da problemática da identidade e da diferença no pensamento francês, Todorov (1989) constata que enquanto "a pluralidade das culturas, no interior de um Estado, não conduz necessariamente ao conflito [...] a pluralidade das raças coloca um, grave, desde que se sobreponha - e esse é normalmente o caso - a uma estratificação social real". Ainda segundo Todorov (1989:119), a solução desse grave problema passaria pela mestiçagem. De certo modo, a situação empírica que tomamos para análise permite testar, em toda a sua complexidade concreta, essa avaliação otimista em relação à "mestiçagem".

5. No caso cabo-verdiano se impõe uma análise à semelhança da análise de Pécault para o campo intelectual brasileiro que dê conta da multiplicidade de interesses em jogo. "Seria igualmente plausível detectar, na origem de cada engajamento, alguma con- 
cepção de interesse, mas este não poderia ser reduzido à busca de um emprego público sem prejuízo de se esquecer da variedade dos tipos de interesses e das estratégias para consegui-los. Essa complexidade não é surpreendente, pois decorre da inexistência de uma justaposição entre um campo intelectual regido por suas próprias modalidades institucionais de legitimação, e um campo político igualmente submetido a outras modalidades de legitimação. De imediato se produziu, não uma interferência, mas uma mescla. Toda as estratégias individuais se colocam sobre os dois registros" (Pécaut, 1990:89).

6. No Ocidente, à medida que o Estado nasce de "numa constelação intelectual marcada pela aliança entre direito romano, filosofia escolástica e doutrina cristã do 'corpo místico' a autoridade tende a ser pensada em contraste com as propriedades das pessoas naturais vulneráveis à degradação e à morte, ou simplesmente ao erro, o pensamento político foi levado a se atribuir explicitamente, a ponto de quase torná-lo seu próprio objeto, o tratamento de 'ficções': a ordem social (civil ou política) faz existir corpos organizados, tem esses privilégios de escapar de forma relativa, pelo menos, ao tempo. É o caso das 'ordens', das corporaçôes, sociedades e igreja [...] ficçôes na qual a propriedade de generalização tem por correlato a propriedade de universalização [...]" (Pinto, 1986).

7. “Tomar a nação como unidade natural da história é recuperar parte do sentido original da natio, que etimologicamente gravita no mesmo campo semântico de natura (natureza)" (Trajano Filho, 1993:3).

8. E até a possibilidade de se acionar recursos mais distantes e poderosos entram no imaginário da proteção clientelística. Na década de 40, Pedro Cardoso, um dos mais prestigiados intelectuais cabo-verdianos, vai aos EUA "pedir auxílio para seu povo". Arquétipo da intervenção a favor do "povo cabo-verdiano" junto a instâncias externas é sobre esse tipo de prática que se molda após a independência o imaginário da proteção que os governantes podem dar à população.

9. Nesse sentido, a luta pela incorporação numa grande nação africana que incluísse toda a África do Oeste teria instaurado um princípio de identidade profundamente diferenciado. Nenhum dos agentes do nacionalismo cabo-verdiano aposta seriamente nessa possibilidade.

\section{Referências bibliográficas:}

ANDERSON, Benedict (1993). Comunidades imaginadas: Reflexiones sobre el origen y la difusion del nacionalismo. México, Fondo de Cultura Económica.

ANJOS, José Carlos G. dos (2002). Intelectuais, literatura e poder em Cabo Verde: lutas de definição da identidade nacional. Porto Alegre (Brasil), UFRGS/IFCH, Praia (Cabo Verde), INIPC.

APPIAH, Kwame Anthony (1997). Na casa de meu pai. Rio de Janeiro, Contraponto.

BARTH, Fredrik (1976). Los grupos étnicos y sus fronteras: la organizacion de las diferencias culturales. México, Fondo de Cultura Económica.

BOAS, Franz (1940). Race, language and culture. New York, Macmillan.

BOURDIEU, P. (1989). Poder simbólico. Lisboa, Ediel. 
BOURDIEU, P. (1993). "Esprits d'Etat: genèse et struture du champ bureaucratique. Actes de la Recherche en Sciences Sociales.

DEZALAY, Yves (1995). Sociologie de l'internationalisation du champ de l'expertise. Centre de Sociologie de l'Éducation et de la Culture.

DUARTE, Vera (1994). "O escritor cabo-verdiano hoje: As transformações no mundo e os seus reflexos na vida literária”. Pré-textos. Praia, Associação dos Escritores Cabo-verdianos, junho.

FOUCAULT, Michel (1987). A arqueologia do saber. Rio de Janeiro, Forense Universitária.

FREYRE, Gilberto (1957). Casa-Grande \& Senzala. Lisboa, Coleção Livro do Brasil.

GEERTZ, C. (1978). A interpretação das culturas. Rio de Janeiro, Zahar.

LABAN, Michel (1992). “Cabo Verde: encontro com escritores”. Porto, Fundação Eng. Antônio de Almeida.

LAGROYE, Jacques (1985). “La légitimation”. In M. Grawitz \& J. Leca (eds.), Traité de Science Politique: la science politique, science sociale, l'ordre politique. Paris, Presses Universitaires de France.

LEGENDRE, Pierre (1976). Jouir du povoir. Paris, Minuit.

MALINOWSKI, B. (1976). Argonautas do Pacífico Ocidental: relato do empreendimento e da aventura dos nativos do arquipélago da Nova Guiné Melanésia. São Paulo, Editora Abril.

MARTIN, Denis-Constant (1992). "Le choix d'identité". Revue Française de Science Politique, vol 42, no 4, pp. 581-593.

MARTÍNEZ-ECHAZÁBAL, L. (1996). "O culturalismo dos anos 30 no Brasil e na América Latina: deslocamento retórico ou mudança conceitual”. In M. C. Maio \& R. V. Santos (orgs.), Raça, Ciência e Sociedade. Rio de Janeiro, FIOCRUZ/CCBB, pp. 107-124.

MAUSS, M. (1974). "Ensaio sobre a dádiva. Forma e razão da troca nas sociedades arcaicas”. Sociologia e Antropologia, vol. 5, no 2.

MINTZ, S. \& PRYCE, S. (eds.) (1985). Caribbean contours. Baltimore, Johns Hopkins University Press.

NEIBURG, F. (1997). Os intelectuais e a invenção do peronismo: estudos de antropologia social e cultural. São Paulo, EDUSP.

NIANE, Boubacar (1995). "Le transnational, signe d'excellence? Le processus de disqualification et de désengagement de l'Etat sénégalais dans la formation des cadres”. In D. Broady; M. Saint-Martin \& M. Palme (orgs.), Les elites: formation, reconversion, internationalisation. Paris, CSEC-EHSS/Stockholm, FUKS, pp. 95-112.

NIANE, Boubacar (1995). "L'elite senegalaise face à l'international”. In D. Broady; M. Saint-Martin \& M. Palme (orgs.), Les Elites: formation, reconversion, internationalisation. Paris, CSEC-EHSS/Stockolm, FUKS, pp. 193-202.

PÉCAUT, Daniel (1990). Os intelectuais e a política no Brasil: entre o povo e a Nação. São Paulo, Editora Ática.

PINTO, L. (1986). "Une fiction politique: la nation; à propos des travaux de Jenö Szücs”. Actes de la Recherche en Sciences Sociales, no 64, setembro, pp.45-50. 
José Carlos Gomes dos Anjos

SANSONE, L. (1996). "As relações raciais em Casa Grande \& Senzala revisitadas à luz do processo de internacionalização e globalização”. In M. C. Maio \& R. V. Santos (orgs.), Raça, Ciência e Sociedade. Rio de Janeiro, FIOCRUZ/CCBB, pp. 207-218.

SHAFER, Boyd C. (1955). Nationalism: myth and reality. London, Victor Gollanez.

SMITH, Anthony D. (1979). Nationalism in the twentieth century. New York, New York University Press.

SOUSA, Henrique Teixeira de (1958). "Cabo Verde e sua gente". Boletim Cabo Verde, no 108 e 109. Praia, Imprensa Nacional de Cabo Verde.

TODOROV, Tzvetan (1989). Nous et les autres. La réflexion française sur la diversité humaine. Paris, Seuil.

TRAJANO FILHO, Wilson (1993). "Rumores: uma narrativa de nação”. Série Antropologia, no 143 , Brasília.

WOLF, F. R. (1980). "Relaciones de parentesco, de amistad y de patronazgo en las sociedades complejas”. In M. Banton (comp.), Antropología social de las sociedades complejas. Madrid. 